more frequent in southern than in northern parts, a second or supplementary brood is formed in one season; as the butterfly lays eggs for some time, and all the females are not born at once, the earliest progeny of the earliest females may not infrequently be able to mature in the same season in time for the production of a second brood. This would seem to be a provision on the part of nature to give the species a better chance. That they need it is perhaps evidenced by the fact that the black-veined orange species, which are almost universally more numerous in individuals than the others, have, in regions where one brood is the normal condition of their fellows, always two broods.

But this is not the only advantage the black-veined orange species have, so that we cannot fairly ascribe their greater numbers to this alone. Their very colors are an advantage to them, for in them they mimic species of $E u$ ploeinae, which possess a taste and perhaps an odor offensive to birds and other insectivorous animals; the mimicry is very striking indeed, and is the more remarkable from the fact that the northern species resembles the only species of Euploeinae found in the region it inhabits, while the southern species as well as the southernmost examples of the northern species, resemble another which is more common in the region they inhabit.

It is indeed possible that one of the normally colored species of Basilarchia, one that has least conspicuously contrasted colors, though resplendent with blue and green, is specially protected by the various other devices we have recounted; for certainly it is itself mimicked by one sex of a butterfly of another very distinct group, viz: Semnopsyche diana.

\title{
DESCRIPTION OF THE LARVA OF SPHINX LUSCITIOSA.
}

BY CAROLINE G. SOUIE, BROOKLINE, MASS.

This larva was found on a poplar shoot, at Sugar Hill, N. H., 2 r July I 887 .

It was then $18.5 \mathrm{~mm}$. long, slender, and green. The head was triangular, pale green, with a pale yellow stripe on each side. The body was brighter green, covered with white granulations, these being less numerous ventrally.

There were seven oblique lines of pale yellow, edged above with green darker than the body, and the last one extended to the tip of the caudal horn. A clear yellow horizontal line on the first three segments, was continued very faintly to the last segment.

The anal shield was of a bluer green than the body, and edged with white.

The feet and props were green; the caudal horn was pinkish above, green beneath, and lined on each side with yellow. Spiracles almost invisible. 
The larva moulted on 25 July, and was $25 \mathrm{~mm}$. long and of the same colors and marks as before.

On 27 July faint lines of a reddish color began to appear above the oblique yellow lines.

On 30 July the larva was $44 \mathrm{~mm}$. long, and ate voraciously. The tips of the feet had become red. The yellow stripes on the head had grown very bright.

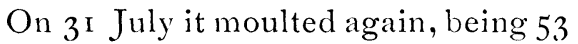
$\mathrm{mm}$. long.

The mouth parts were black; the yellow face-lines were edged with black; and the caudal horn had a black line on each side instead of a yellow line. Other marks as before.

On 2 August the colors had changed somewhat.

The face-lines had become pale green edged with black - rather faint - ; the seven obliques were white edged above with pinkish lilac; the yellow horizontal line had gone from the first three segments, and those segments, as well as the lower half of all the others, were marked with tiny white dots, each encircled with black.

The props had a faint purplish tinge. The spiracles were red.
The head had grown more round, with a slight indentation on top - not enough to call the head bifid.

On 4 August the larva was $62.5 \mathrm{~mm}$. long, and the marks were brighter. The caudal horn was short in proportion to the size of the caterpillar.

On ro August the length of the larva was $87.5 . \mathrm{mm}$., and the marks were unchanged.

On I 2 August it began to be restless, and on I3 August it went into the ground during the night, but re-appeared again on the 14 th, though it ate nothing.

On 5 August it had gone into the ground again, and 2 I August it had become a bright mahogany-colored pupa, $37.5 \mathrm{~mm}$. long, with a tonguecase $3 \mathrm{~mm}$. in length and lying close against the pupa.

On 7 June, r888, the pupa had grown much darker and duller, and on Io June, at about 8.30 A.M., a fine $q$ emerged.

The larva was fed entirely on poplar.

I had netted a $\delta$ imago in a field near the poplar where I found this larva, only a few days before, flying at almost noon, and feeding at kale blossoms.

\section{THE. ARRANGEMENT OF THE NEW ENGLAND SPECIES OF 'THANAOS.}

\section{BY SAMUEL HUBBARD SCUDDER, CAMBRIDGE, MASS.}

An examination of the androconia concealed in the costal fold of the fore wing in the species of this genus has brought to light some very curious facts, showing how closely related, as far as these scales are concerned, some of the 

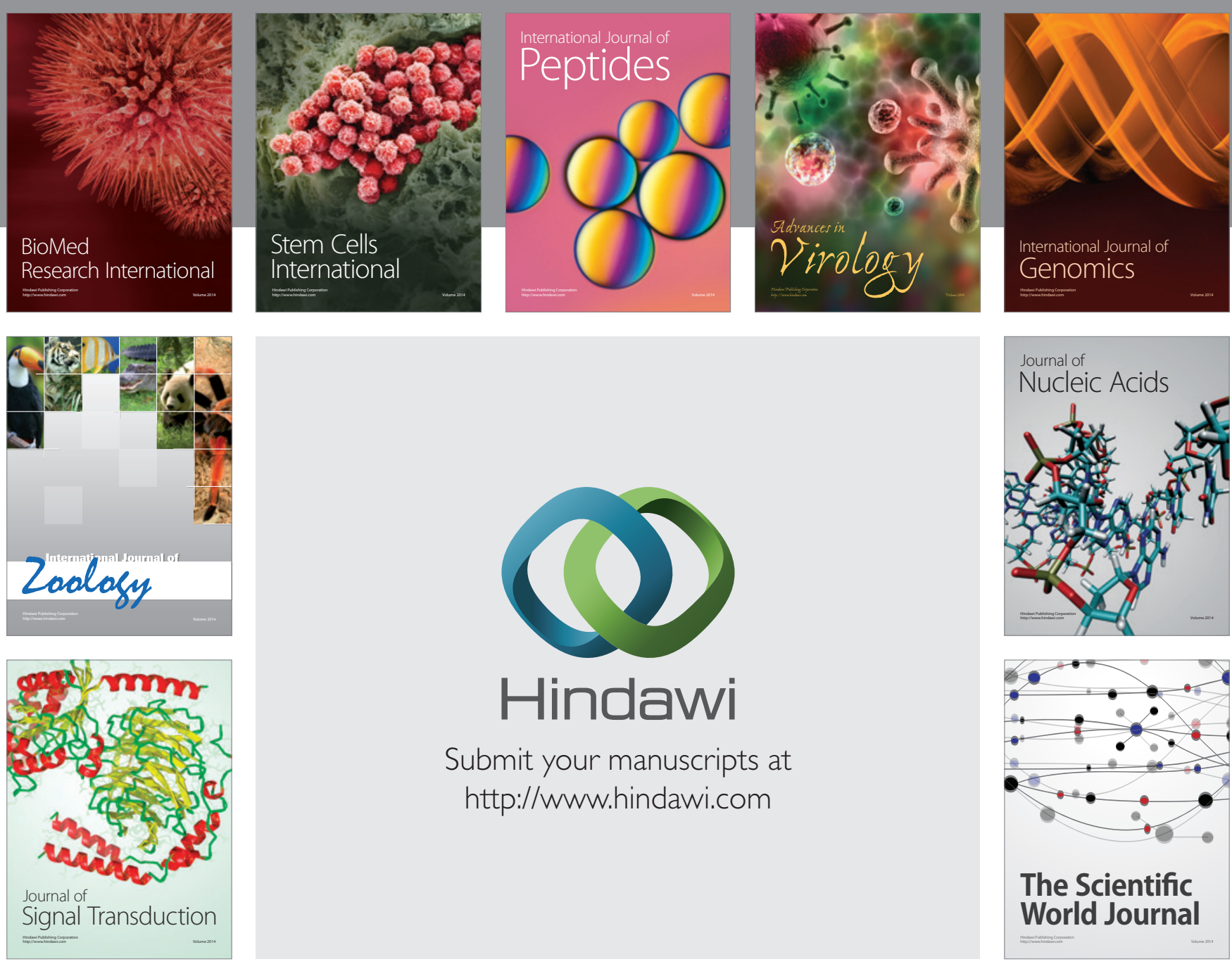

Submit your manuscripts at

http://www.hindawi.com
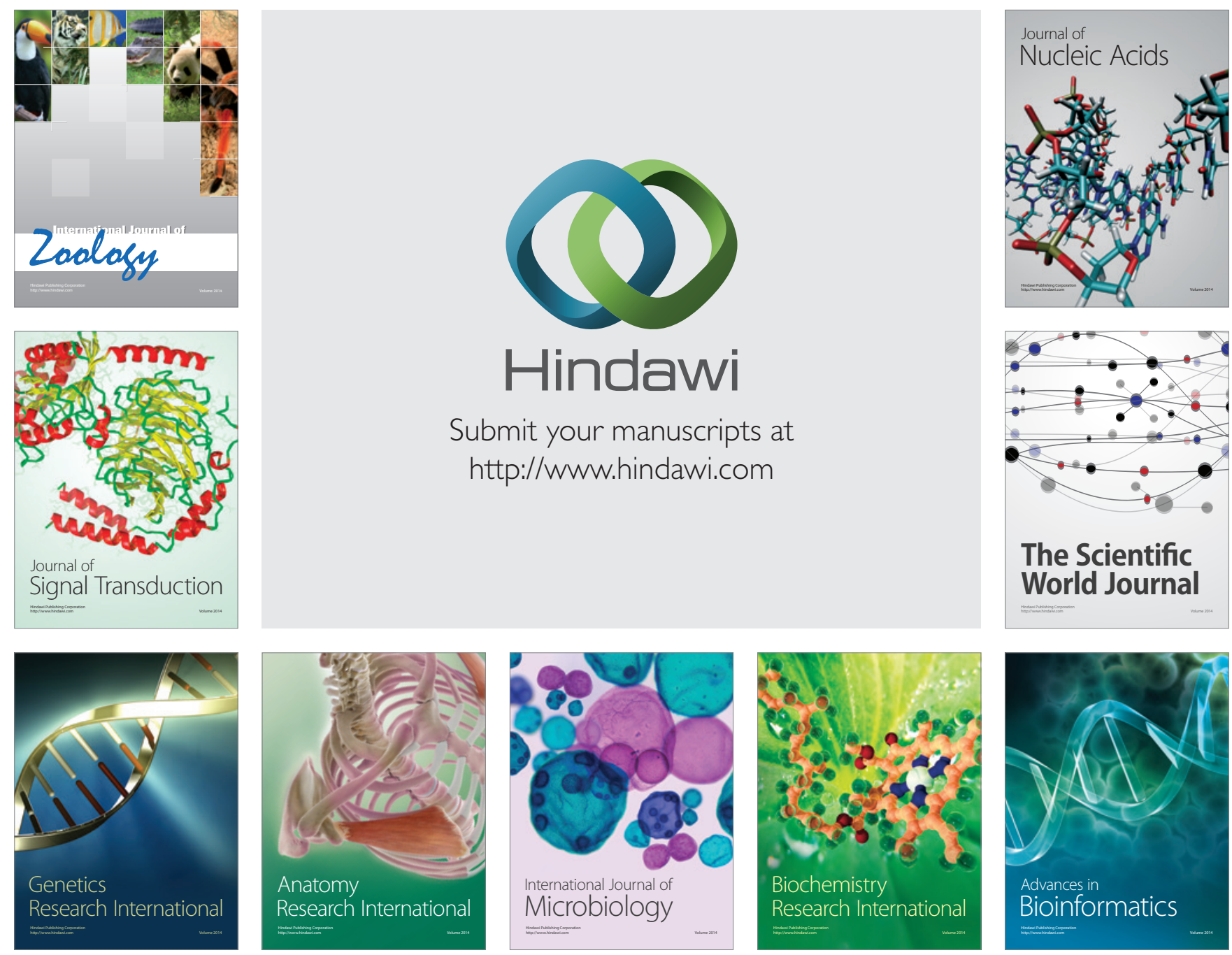

The Scientific World Journal
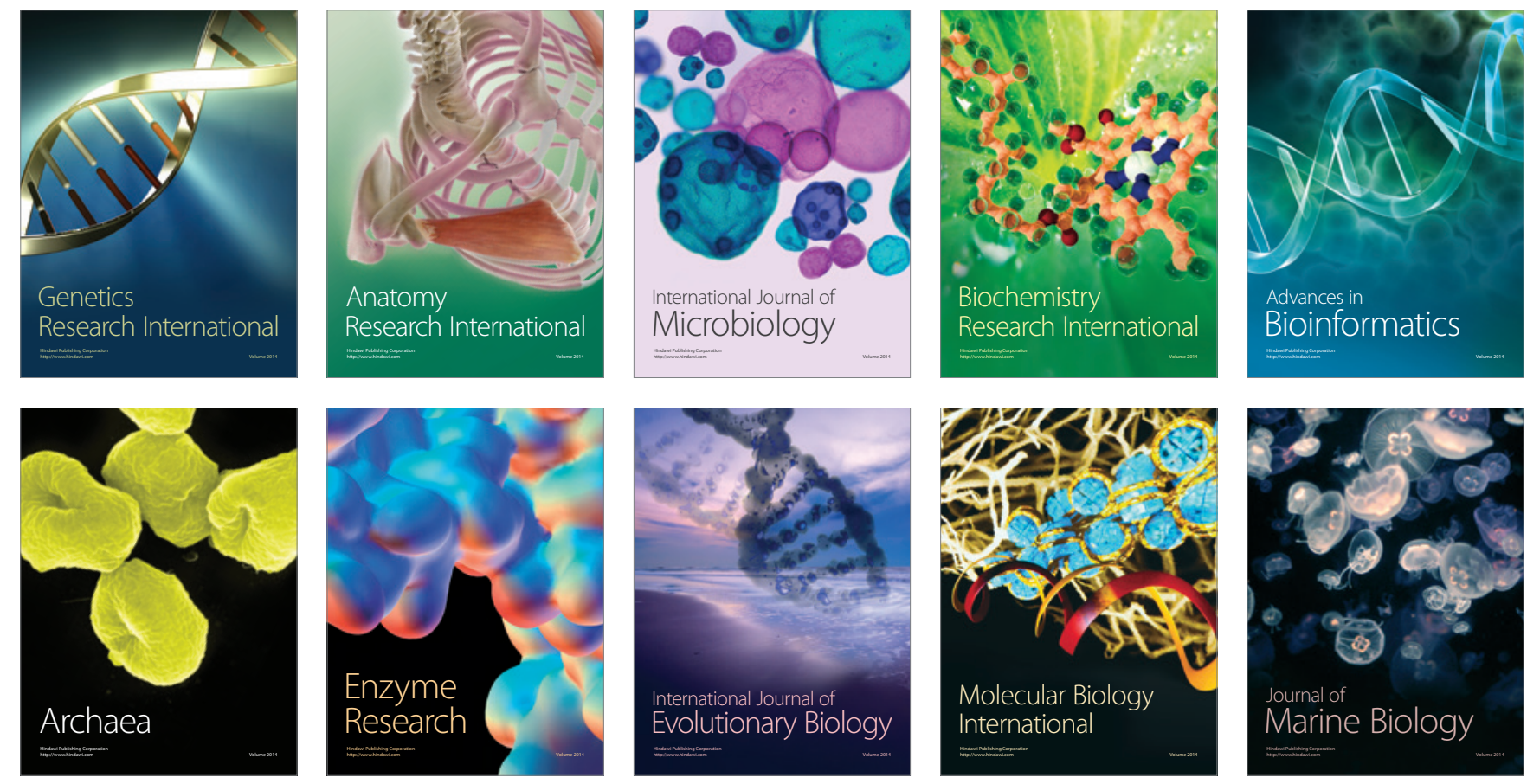